Preprints of the

Max Planck Institute for

Research on Collective Goods

Bonn 2009/17

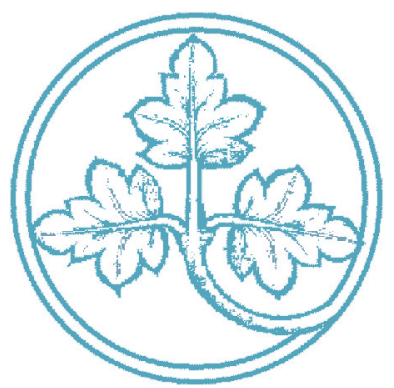

Parallel Constraint

Satisfaction in Memory-

Based Decisions

Andreas Glöckner

Sara D. Hodges

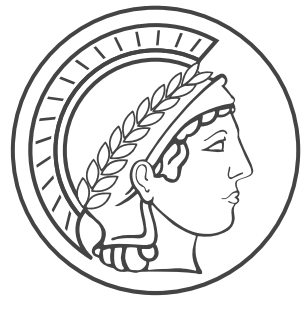




\title{
Parallel Constraint Satisfaction in Memory-Based Decisions
}

\author{
Andreas Glöckner / Sara D. Hodges
}

June 2009 


\title{
Parallel Constraint Satisfaction in Memory-Based Decisions
}

\author{
Andreas Glöckner ${ }^{\star}$ / Sara D. Hodges ${ }^{\ddagger}$
}

\begin{abstract}
Three studies sought to investigate decision strategies in memory-based decisions and to test the predictions of the parallel constraint satisfaction (PCS) model for decision making (Glöckner \& Betsch, 2008). Time pressure was manipulated and the model was compared against simple heuristics (take the best and equal weight) and a weighted additive strategy. From PCS we predicted that fast intuitive decision making is based on compensatory information integration and that decision time increases with increasing inconsistency in the decision task. In line with these predictions we observed a predominant usage of compensatory strategies under all time pressure conditions and even with decision times as short as 1.7 seconds. For a substantial number of participants, choices and decision times were best explained by PCS, but there was also evidence for use of simple heuristics. The time pressure manipulation did not significantly affect decision strategies. Overall, the results highlight intuitive, automatic processes in decision making and support the idea that human information-processing capabilities are less severely bounded than often assumed.
\end{abstract}

Keywords: Memory-Based Decision Making, Parallel Constraint Satisfaction, Fast and Frugal Heuristics, Automatic Information Integration

Address Correspondence to: Andreas Glöckner, Max Planck Institute for Research on Collective Goods, Kurt-Schumacher-Str. 10, D-53113 Bonn, Germany, Phone: +49-(0) 228 / 91416 857, E-mail: gloeckner@coll.mpg.de

$\$ \quad$ University of Oregon 
Decision making entails integrating probabilistic information. Empirical evidence indicates that individuals employ multiple different strategies to accomplish this (Payne, Bettman, \& Johnson, 1988). Some of these strategies are mathematically complex such as the weighted additive rule (WADD) of utility theory. Others, such as the lexicographic rule (LEX, Fishburn, 1974), elimination-by-aspects (Tversky, 1972), or the equal weight rule (EQW, Fishburn, 1974), involve considerably fewer computational steps. Considering deliberate processes only, it is reasonable to assume that the mental effort for a decision strategy can be approximated by the number of computational steps to apply the strategy (Payne et al., 1988). Therefore, the application of a WADD strategy should be much more effortful and time consuming than the application of, for instance, a LEX or an EQW heuristic. Findings in probabilistic inference decisions (Glöckner \& Betsch, 2008c) and preference decisions under risk (Glöckner \& Betsch, 2008a) indicate, however, that individuals are able to apply WADD strategies very quickly. Decision times are far below the times that would be necessary for a sequence of deliberate calculations. These findings indicate that individuals might apply intuitive-automatic decision strategies that partially rely on automatic processes (e.g., Kahneman \& Frederick, 2002; Schneider \& Shiffrin, 1977) and approximate weighted additive information integration without a deliberate calculation of weighted sums (Hammond, Hamm, Grassia, \& Pearson, 1987). Glöckner and Betsch (2008b) have argued that the underlying cognitive processes can be modeled using parallel constraint satisfaction (PCS) networks (Holyoak \& Simon, 1999; McClelland \& Rumelhart, 1981).

In the current paper, we investigate specific predictions of the PCS model (Glöckner \& Betsch, $2008 \mathrm{~b}$ ) in memory-based probabilistic inference decisions concerning choices and decision times. First, studies of memory-based decisions are reviewed and critically evaluated. Then, the PCS model is briefly introduced and hypotheses are derived. Three studies are reported in which we test these hypotheses against hypotheses derived from the take the best (TTB) heuristic (Gigerenzer \& Goldstein, 1996, 1999), the EQW heuristic, and a WADD strategy.

\section{Research on Memory-based Probabilistic Inference Decisions}

Much research on probabilistic inference decisions has been conducted using the city-size task (Gigerenzer \& Goldstein, 1996). In this task individuals have to decide which of two cities has more inhabitants. Assuming they do not already know the exact number of inhabitants, people might use information about the cities that has a certain predictive power for estimating the size of the cities (cues). Individuals could try to remember, for instance, if one of the cities is a state capital, given that state capitals are on average larger than non-capitals. This would be considered a memory-based decision because information about the city (cue value) has to be retrieved from memory. In contrast, if the same information were directly presented to the person, for instance on a computer screen, this would be considered a decision based on given information (Bröder \& Schiffer, 2003b).

To solve probabilistic inference tasks, individuals may have to consider probabilistic information from multiple different cues. Research has focused mainly on cues with dichotomous cue values 
(i.e., yes / no). Individuals might take into account cue validities, that is, the estimated predictive power of the cues (defined as the conditional likelihood of a positive criterion value given a positive cue value). According to a TTB heuristic (a special case of LEX), individuals only retrieve information on the most valid cue and select the option scores higher on this cue. The second cue is retrieved only if the first cue does not differentiate between options, and so on for the third cue, etc. The EQW heuristic assumes that people only add up positive and negative cue values of both options and chose the option with the higher sum. The deliberate WADD strategy assumes that individuals calculate the weighted sum of cue values and cue validities for each option and select the option with the higher weighted sum.

In contrast to a large body of evidence on decisions from given information (e.g., Bergert \& Nosofsky, 2007; Bröder, 2000, 2003; Bröder \& Schiffer, 2003b; Glöckner, 2006; Glöckner \& Betsch, 2008c; Newell, Weston, \& Shanks, 2003; Rieskamp, 2006; Rieskamp \& Hoffrage, 1999 ), only a few studies have been conducted to investigate strategies of memory-based probabilistic inference decisions. In one of the first investigation of memory-based decisions, Bröder and Schiffer (2003b) developed a research paradigm in which participants learned information about target people. Participants used this information later on to decide which of these targets committed a certain crime. The experiments revealed that the majority of participants used simple heuristics, particularly TTB. A significant shift in decision strategies was observed between memory-based decisions and decisions from given information. In memory-based decisions a higher proportion of TTB users and a lower proportion of WADD users were observed. Furthermore, the representation format of the cues had an influence on decision strategies. In the "learning phase," attributes of the target people (e.g., type of jacket, shirt color) were presented either verbally or in the form of a picture of the person which showed the various the attributes. The latter was meant to induce an image-based representation format and led to a higher percentage of WADD users, something that Bröder and Schiffer explained by incorporating automatic processes as suggested in image theory (Beach \& Mitchell, 1996) which might result in weighted compensatory information integration.

Bröder and Gaissmaier (2007) further investigated decision strategies in memory-based decisions by conducting a reanalysis of five earlier studies (Bröder \& Schiffer, 2003b, 2006), plus one new experiment, all of which used essentially the same procedure as the studies reported above. The reanalysis revealed that the majority of participants used simple heuristics instead of more effortful weighted compensatory strategies (198 TTB users, 83 EQW users, 90 WADD users and 44 participants who appeared to guess randomly). Furthermore, decision times indicated that for TTB users, decision times increased with the number of cues needed to differentiate between the options when using this strategy. This provided converging evidence for the strategy classification. It was further interpreted as support for the general claim that information is serially processed and that the number of necessary calculations determines decision time (cf. Payne et al., 1988).

For several reasons we suspected that these results might not generalize to other settings. The criminal case materials used in these studies incorporated several specific features that are not 
present in many every-day situations. First, the cues used were not intended to have any natural predictive power (cue validity) for the decision criterion (guilty vs. not guilty) and they were conceptually not binary cues (a cue such as shirt color could have numerous possible values whereas whether a city is a state capital or not is a yes/no question). Individuals were explicitly informed about cue validities, but only after they had learned the cue values. Individuals learned, for instance, that Anne wore a white shirt and were then later informed that four eyewitnesses had seen the perpetrator wearing a white shirt. Therefore, the decision task was rather demanding: individuals first had to remember the cue validities and then had to retrieve the cue values they had learned earlier. In contrast, in more natural settings, like the city-size decisions, cues have a priori cue validities which are readily meaningful and they are often binary. This might facilitate the application of automatic processing. Hence there is evidence demonstrating the use of TTB as a common strategy in memory-based decisions, but perhaps only under circumstances that lack key elements of natural settings.

\section{The Parallel Constraint Satisfaction (PCS) Model for Decision Making}

Glöckner and Betsch (2008b) have argued that the cognitive processes underlying intuitive decision making can be modeled by PCS networks (for earlier PCS approaches to judgment and decision making see Holyoak \& Simon, 1999; Simon, Snow, \& Read, 2004; Thagard, 1989; Thagard \& Millgram, 1995). The suggested PCS model consists of three (or possibly four) steps: When individuals encounter a decision situation, they first activate associated and salient information in memory and form a mental representation that incorporates any given information, plus information stored in memory. In the second step, automatic processes of parallel constraint satisfaction take place that lead to the maximization of consistency in the representation. Consistency in this context means that pieces of information do not contradict each other. Consistency in a decision situation can mainly be reached by dominance structuring (cf. Montgomery, 1989; see also Svenson, 1992), which occurs by modifying information so that one option clearly dominates the other(s). By spreading activation, inconsistency between pieces of information is reduced and a consistent (or balanced) mental representation is formed. In the third step, the decider consults the resulting mental representation in which one option usually clearly dominates and chooses this option. If the consistency of the resulting mental representation is below a certain threshold, deliberate construction processes are activated, constituting a fourth step. Deliberate constructions are used to change the structure of the network. However, for pragmatic reasons, the simulation reported below only considers the first three steps.

In the following section, we present results from simulations of the model that were calculated to derive specific decision time predictions for the later reported empirical tests. 


\section{Simulations}

\section{The model and the updating algorithm}

For the simulation of simple probabilistic inferences in a PCS model (Glöckner \& Betsch, 2008b), the network structure presented in Figure 1 and an iterative activation updating mechanism (PCS algorithm; McClelland \& Rumelhart, 1981) were used. Boxes represent nodes with variable activations. Lines represent (fixed) links between nodes and are all bidirectional. Connection weights can range from -1 to +1 and are labeled $w$. Connections between options and cues represent cue information, indicating a positive or negative predictive weight of the cue for the respective option. Links between the general validity node and the cues represent initial cue validities. Using the iterative updating algorithm, coherence is produced in the network by changing activations $(a)$ of the nodes. ${ }^{1}$

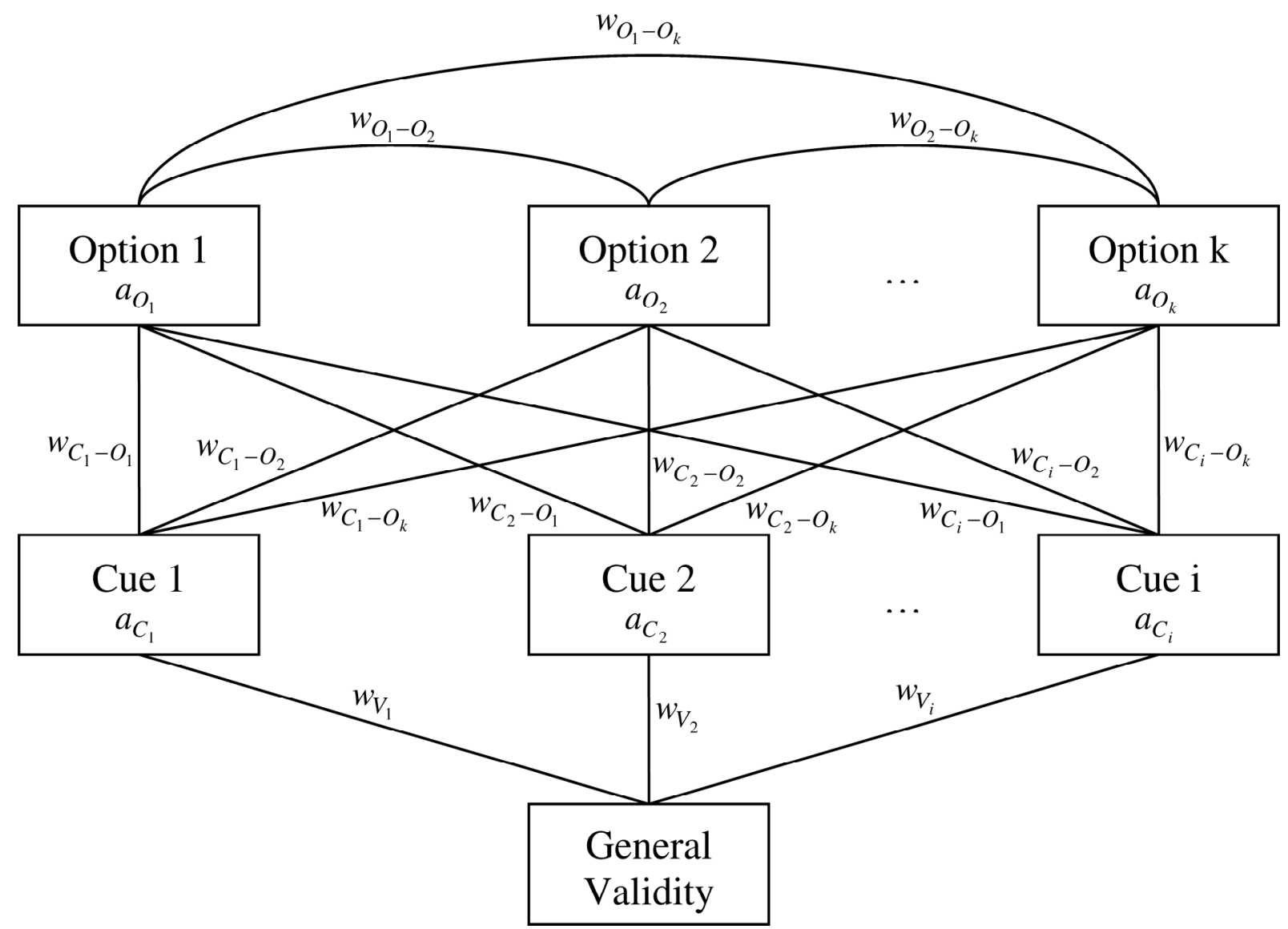

Figure 1. The picture shows the structure of a general parallel constraint satisfaction network model for probabilistic inferences as postulated by PCS. Boxes represent nodes, for which activation $a$ is changed in the process of parallel constraint satisfaction. Lines represent links between nodes which can have different strength $w$ and can be excitatory and inhibitory.

Note, that PCS networks take the network structure as given and simulate only the ad-hoc interpretation given this evidence structure (Shultz \& Lepper, 1996). Changes in the structure of the network (i.e., in the link weights) that might be caused by long-term learning are not part of model (cf. supervised or unsupervised learning models). Hence, PCS model are in almost all respects different from the simple connectionist model which was already tested against fast and frugal heuristics by Rieskamp (2006). 
The iterative updating algorithm uses a sigmoid activation function proposed by McClelland and Rumelhart (1981):

$a_{i}(t+1)=a_{i}(t) *(1-$ decay $)+\left\{\begin{array}{ccc}\text { if } & \text { input }_{i}<0 & \text { input }_{i} *\left(a_{i}(t)-\text { floor }\right) \\ \text { if } & \text { input }_{i} \geq 0 & \text { input }_{i} *\left(\text { ceiling }_{-} a_{i}(t)\right)\end{array}\right.$

$a_{i}(t)$ represents the activation of the node $i$ at iteration $t$. The parameters floor and ceiling stand for the minimum and maximum possible activation (in our model set to -1 and +1 , respectively). $\operatorname{Input}_{i}(t)$ is the activation node $i$ receives at iteration $t$, which is computed by summing up all products of activations and connection weights $w_{i j}$ for node $i$. Decay is a constant decay parameter.

$\operatorname{input}_{i}(t)=\sum_{j=1 \rightarrow n} w_{i j} * a_{j}(t)$

\section{Method}

In the simulation, the differences between initial cue validities were systematically manipulated. Separate simulations were run for the six cue patterns depicted in Table 1 (top). The cue patterns represent all possible cue patterns in decision tasks with two options and three cues in which each option has at least one positive cue and no cue has positive values for both options.

\section{Table 1}

Cue Patterns Used in the Simulation and in Experiment 1 to 3

\begin{tabular}{|c|c|c|c|c|c|c|c|c|c|c|c|c|}
\hline & \multicolumn{2}{|c|}{ Pattern 1} & \multicolumn{2}{|c|}{ Pattern 2} & \multicolumn{2}{|c|}{ Pattern 3} & \multicolumn{2}{|c|}{ Pattern 4} & \multicolumn{2}{|c|}{ Pattern 5} & \multicolumn{2}{|c|}{ Pattern 6} \\
\hline & $A$ & $B$ & $\bar{A}$ & $B$ & $A$ & $B$ & $\bar{A}$ & $B$ & $A$ & $B$ & $\bar{A}$ & $B$ \\
\hline$\overline{\text { Cue } 1}$ & + & - & + & - & - & - & + & - & + & - & + & - \\
\hline Cue 2 & - & + & - & - & + & - & - & + & - & + & + & - \\
\hline Cue 3 & - & - & - & + & - & + & - & + & + & - & - & + \\
\hline
\end{tabular}

Decision time predictions PCS

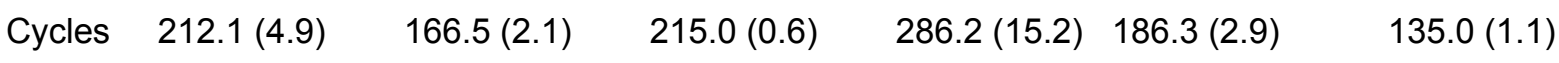

$\begin{array}{lllllll}\text { Estimate } & 0.5 & -1.5 & 0.5 & 3.5 & -0.5 & -2.5\end{array}$

Note. A and B represent the two options. Cue 1 is the most valid cue, cue 2 is the second most valid cue and cue 3 is the least valid cue. Decision time predictions for the cue patterns are shown in the lower part of the table. Cycles mean iterations in the PCS simulation were averaged over 525 simulations per cue pattern. $S D$ for 21 average values for each level of initial validity of cue 1 is given in parentheses. Estimate is a rough transformation of cycles to a scale of contrast weights that add up to zero.

In the simulation we used parameters roughly oriented on the ones used by McClelland and Rumelhart (1981). According to Figure 1, cue information (links between cues and options, e.g., $\left.w_{\mathrm{c} 1-\mathrm{o} 1}\right)$ were represented by link weights of +0.01 and -0.01 . The inhibition between the options 
was represented by a strongly negative link $w_{01-02}=-0.10$. The decay parameter was set to 0.10 . The stability criterion used for terminating the process was 10 cycles with no energy changes bigger than $10^{-6}$. In the simulation, the validity parameter of cue $1 w_{\mathrm{v} 1}$ was manipulated from 0.40 to $0.60 .^{2}$ With this manipulation, the advantage of cue 1 over the other cues was systematically increased. For each level of cue $1, w_{\mathrm{v} 3}$ was varied from 0.01 to 0.05 and $w_{\mathrm{v} 2}$ was varied from 0.10 to 0.14 in order to add some variation on each level of $w_{\mathrm{v} 1}$ and to reduce the impact of a number-specific outlier in decision time predictions. All analyses are based on the average of the resulting 25 crossed constellations for each level of $w_{\mathrm{v} 1}$. Overall, we simulated a total of 525 cue validity constellations per cue pattern.

\section{Results and Interpretation}

Choice predictions. Choice predictions were calculated by comparing the activation of the two option nodes after the network stabilized. In cue patterns 1, 2, 3, 5, and 6, all predicted choices were for option A. In cue patterns 4, predicted choice for option A increased with increasing validity of cue 1 (Figure 2). Thus, the model's predictions are in line with the predictions of weighted additive models. ${ }^{3}$

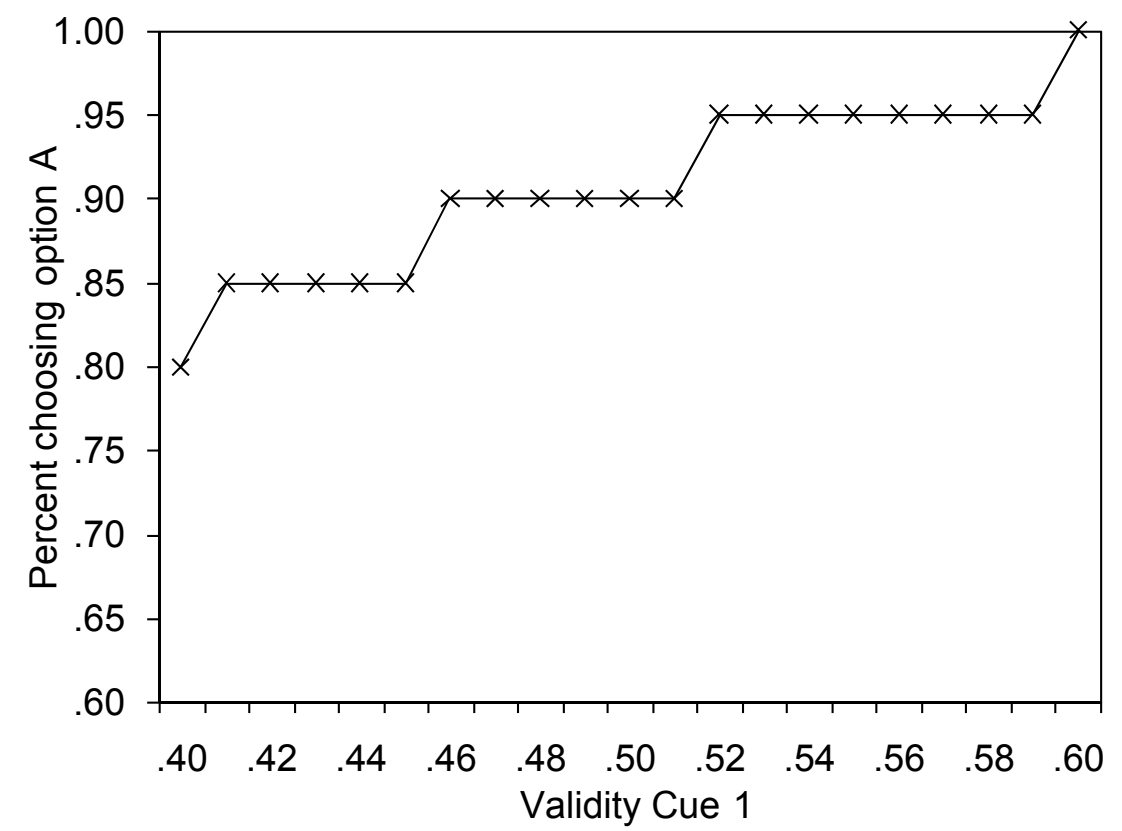

Figure 2. Choice predictions for cue pattern 4

2 Note that link weights (which represent initial validity parameters in the model) are not numerically identical with cue validities, defined as conditional probabilities. A link weight of zero represents the fact that a cue has no predictive power and is equivalent to a cue-validity of .50.

3 The question of how different "cue validities" (e.g., defined as conditional probabilities, decision weights or log-odds) should be transformed into cue weights in PCS network models is discussed elsewhere (Glöckner, in press). 
Decision time predictions. Decision time predictions were calculated from the number of iterations (cycles) that were necessary to construct a stable solution of the network. The average numbers of iterations for cue patterns are shown in Table 1 (bottom). The PCS model predicts high decision times for cue pattern 4, medium decision times for cue patterns 1, 2, 3, and 5, and low decision times for cue pattern 6. Further simulations with different parameters showed that the general patterns seem to be robust for similar cue hierarchies. The effect of the cue validity manipulation is presented in Figure 3 (left).

Cue validity predictions. As mentioned above, one of the core properties of PCS networks is that the validity of the cues is changed within the decision process (coherence shifts, Simon, Pham, Le, \& Holyoak, 2001). In PCS networks, the resulting posterior cue validity is conceptualized as activation of nodes (whereas priori cue validities are represented by links). The final activations of the node representing cue 2 were analyzed. The manipulations of the cue pattern and the cue validity of cue 1 both influenced the final activation of cue 2 (Figure 3, right). The lowest activation levels are observed for cue patterns 1 and 5 in which the second cue supports the losing option. The highest levels were found for cue patterns 3 and 6 , in which the second cue is on the side of the clearly winning option.
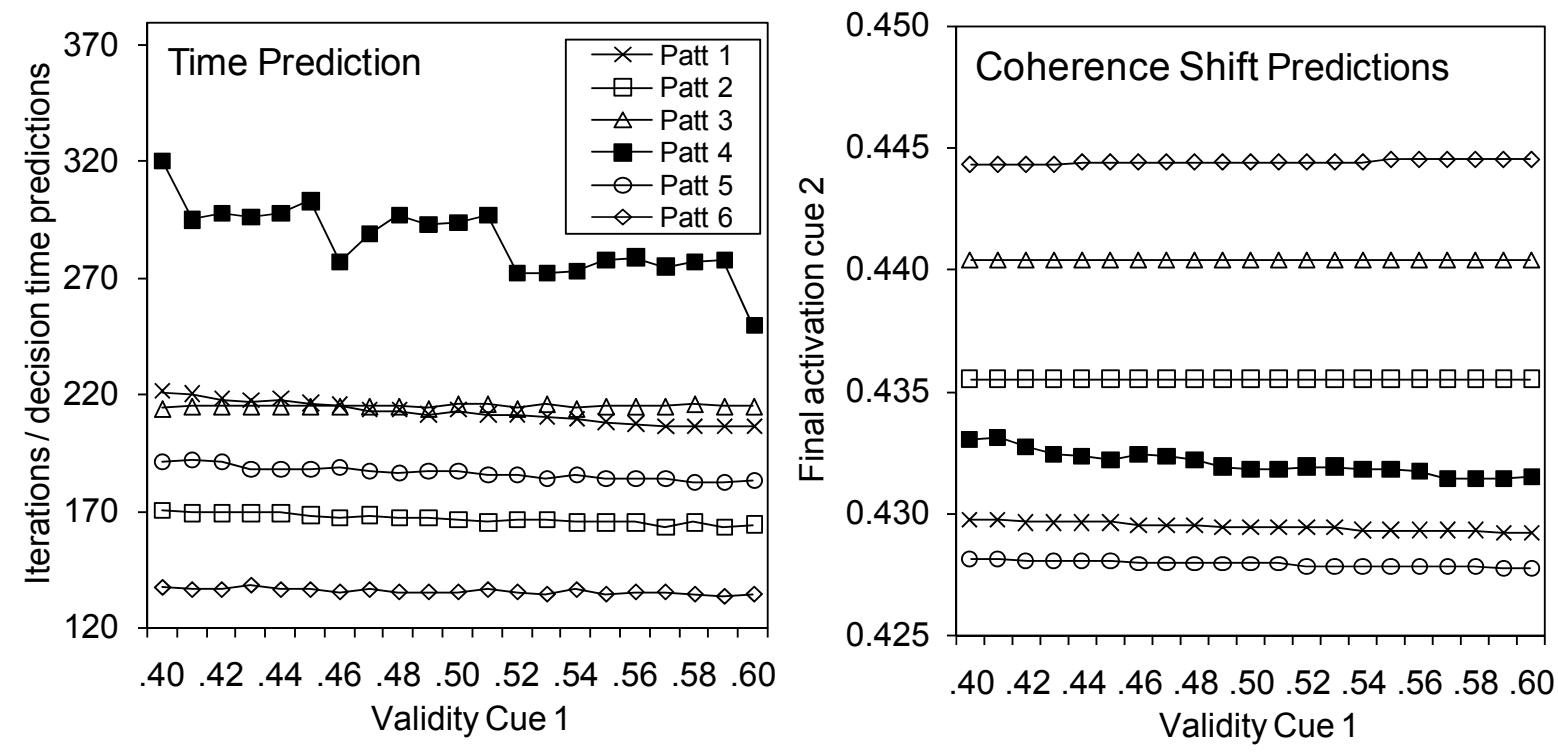

Figure 3. Decision time predictions (left) and coherence shift predictions for cue 2 (right) for cue patterns 1 to 6 . Decision time is estimated by the number of iterations to find a stable solution in the network. Coherence shifts are estimated by the final activation of cue 2 .

\section{Discussion}

Overall, the results converge with the predictions derived from theoretical considerations and earlier simulations of PCS networks (Glöckner, 2006; Glöckner, Betsch, \& Schindler, under review; Holyoak \& Simon, 1999). First, and most important, by applying PCS mechanisms, indi- 
viduals should arrive at choices that take into account all pieces of information according to their validity (approximating a kind of WADD strategy), and they should arrive at these choices rather quickly. Second, decision time should increase as inconsistency in the decision situation increases. In other words, if the cues that speak for one option are almost as strong as cues that speak for the other, then decision times should be longer, whereas decision times should be faster if all cues speak for one option and no dominance structuring is necessary. Finally, the PCS model predicts that subjective cue validities change during the decision process to form a consistent representation. As already mentioned, the last prediction has been extensively tested and is supported by ample of evidence. The first two predictions will be tested in the following experiments.

\section{Methodological Preliminaries}

To allow for strategy classification, predictions concerning choices and decision times for each cue pattern were derived and are summarized in Table 2. For TTB, EQW, and WADD, decision times were derived from the number of computational steps necessary to come to the decision (for details see Glöckner, in press). Note that for pattern 4, choice predictions of WADD and PCS depend on individuals' cue validities. If the most valid cue is considered to be far more valid than the remaining ones, A would be chosen, otherwise B. For the decision time predictions of PCS we use the average prediction derived from the simulation, to avoid giving PCS the advantage of free parameters.

Three experiments were conducted to explore decision strategies in memory-based probabilistic inferences and to test the predictions of the PCS model. In Experiment 1, implicit time pressure was induced by instructing participants to respond as quickly as possible, whereas in Experiment 2 and 3, explicit time limits were applied using a visible timer that counted down participants' remaining available response time. Based on findings for memory-based decisions (Bröder \& Gaissmaier, 2007; Bröder \& Schiffer, 2003b), in Experiment 1, TTB would be expected to be the dominating decision strategy. In contrast, findings of Glöckner and Betsch (2008c) indicate that fast weighted compensatory strategies that are partially based on automatic, intuitive processes (i.e., PCS or other automatic models that implement weighted compensatory information integration) could dominate. Thus, in the first experiment we tested the hypothesis that even under time pressure, fast weighted compensatory strategies are predominantly applied in memory-based decisions with cues that have natural validity. We furthermore expected to find a substantial proportion of PCS users who show choices and decision times to be in line with the predictions of the model. 
Table 2

Predictions of TTB, EQW, WADD and PCS for Choices and Decision Times

\begin{tabular}{|c|c|c|c|c|c|c|}
\hline & \multicolumn{6}{|c|}{ Predictions for choices } \\
\hline & Pattern 1 & Pattern 2 & Pattern 3 & Pattern 4 & Pattern 5 & Pattern 6 \\
\hline TTB & A & A & A & A & A & A \\
\hline EQW & $A: B$ & $A: B$ & $A: B$ & B & A & A \\
\hline WADD & A & A & A & $A / B$ & A & A \\
\hline \multirow[t]{3}{*}{ PCS } & A & $A$ & $A$ & $A / B$ & A & A \\
\hline & \multicolumn{6}{|c|}{ Predictions for decision times (contrast weights) } \\
\hline & Pattern 1 & Pattern 2 & Pattern 3 & Pattern 4 & Pattern 5 & Pattern 6 \\
\hline TTB & -1 & -1 & 5 & -1 & -1 & -1 \\
\hline EQW & 0 & 0 & 0 & 0 & 0 & 0 \\
\hline WADD & 0 & 0 & 0 & 0 & 0 & 0 \\
\hline PCS & 0.5 & -1.5 & 0.5 & 3.5 & -0.5 & -2.5 \\
\hline
\end{tabular}

Note. Patterns 1 to 6 refer to the respective cue patterns in Table 1. In the upper part of the table, predictions for choices are shown. $A$ and $B$ stand for the predicted option. "A:B" indicates no predicted difference between the selection of $A$ or $B$. " $A / B$ " represents the choice of $A$ or $B$ depends on high or low differences between cue validities of the most and the less valid cues. The lower part of the table shows predictions of decision times expressed in contrast weights. Differences in values should only be compared within a decision strategy (within one line of the table) because they represent relative weights comparing different cue patterns for one strategy.

\section{Experiment 1}

\section{Method}

Participants and design. Participants of the first experiment were 20 University of Oregon undergraduate students ( 15 female) between the ages of 18 and 24 . The experiment lasted about 45 minutes and the participants partially fulfilled a course requirement in exchange for their participation. Decision tasks were manipulated within subjects using a 6 (cue pattern) x 4 (version) design, with "version" representing different specific city comparisons that realized the above introduced cue patterns (Table 1).

Materials and procedure. Participants had to decide which of two cities had more inhabitants based on probability cues. Information was provided as to whether a city was a state capital, 
whether it had a university, and whether it had a major league sports team. In order to make the decisions memory-based, participants learned information about 12 unfamiliar German cities ${ }^{4}$ in a preliminary learning phase and then later had to decide which of the two cities was larger when the information was no longer present. The decision tasks always consisted of two options (i.e., cities) and three cues (i.e., information about the presences of state capital, university and major league sports team). Each of the six cue patterns presented in Table 1 was realized by four different combinations of cities resulting in a total of 24 decision tasks. The experiment was completely computer-directed.

Participants were informed that they would learn information about real existing German cities and afterwards they would be asked to recall the information. They were further informed that the three students with the best performance on this task would additionally earn $\$ 20, \$ 10$ and $\$ 5$. The learning phase of the study consisted of repeated learning trials in 4 parts. It started with 10 -second presentations of each of the cities with all three cue values at once. Then in the second part, single cue values were presented for 6 seconds in random order (e.g., "Kassel - has a university"). In the third part of the learning phase, participants had to answer questions about single cue values in random order (e.g., "Does Kassel have a university?") and were provided with feedback. In the fourth part of the learning phase, for each city, participants were asked to recall all three cue values at once. Again, direct feedback was provided on the correctness of the answers. This whole learning procedure was repeated three times. In the third repetition, presentation of single cue values (part 2) was omitted to decrease the overall duration of the study. The resulting learning phase lasted about 25 minutes.

In the subsequent decision phase, participants were asked to decide which of two cities had more inhabitants and were told that correct choices would be rewarded with bonus points that would increase their likelihood of winning the money for best performance. Students were instructed to make accurate decisions and to respond as quickly as possible (Fazio, 1990). No information on the validity of the cues was provided and participants had to construct subjective cue validities from existing knowledge. The 24 decision tasks were presented in random order. Two additional decision tasks were used for warm-up purposes. Only the names of the two cities were presented, and participants had to select one of them with a mouse click. After each decision task participants were asked to indicate how confident they were that their choice was correct on a scale from -100 (very unconfident) to +100 (very confident) using a horizontal scrollbar. Choices, decision times, and confidence judgments were recorded as dependent variables.

Participants were asked in a post-test to recall cue values for all cities. Prior knowledge about the German cities was also measured at this time by asking participants to choose one of three options: (a) I have never heard of this city before, (b) only the name of the city was familiar to me, or (c) I knew more than just the name of the city before the study. Cue validities were explicitly

The cities used in the experiment were Wiesbaden, Mannheim, Rostock, Dortmund, Schwerin, Hannover, Potsdam, Kassel, Leverkusen, Freiburg, Magdeburg and Dresden. Three of 36 cue values were altered from the real values to fit our design. 
measured by indicating how important the cues were for their decision on a scale from -100 (very unimportant) to +100 (very important) using a horizontal scrollbar.

\section{Results}

Learning phase and prior knowledge. Inspection of the results of the post-test revealed that on average $89 \%$ of the cue values were recalled correctly. Thus, it can be concluded that the learning phase was successful. Participants had almost no prior knowledge about the German cities. Overall, $23 \%$ of the ratings indicated that a city name was known; only $2 \%$ indicated that more than the name was known.

Strategy classification. Individuals' decision strategies were analyzed using a maximum likelihood method (Bröder \& Schiffer, 2003a; Wasserman, 2000). ${ }^{5}$ Specifically, we computed the likelihood of each choice vector given each decision strategy and a constant error rate. To conduct the analysis for the strategies TTB and WADD/PCS, the (ordinal) position of the cues was calculated from individuals' explicit cue validity ratings. To test the robustness of this procedure we conducted Monte-Carlo simulations, varying error parameters for explicit cue validities and strategy application. The simulations revealed that the classification method is robust but shows a slight tendency to overestimate TTB usage. ${ }^{6}$ We nevertheless used the method because the bias works against our hypothesis.

The maximum-likelihood analysis revealed choices in line with TTB for two participants, with WADD/PCS for six participants, and with EQW for nine participants. For three participants, the likelihoods for TTB and WADD/PCS were equal. Note, however, that TTB and EQW choices can always be produced by applying the more complex strategies of WADD/PCS with specific weights (i.e., non-compensatory weights or equal weights; see Lee \& Cummins, 2004). We used decision times to further investigate which strategy was actually used by participants who showed choices in line with TTB and EQW for which WADD/PCS could also account (Bergert \& Nosofsky, 2007; Glöckner, 2006, in press). In contrast to Bergert and Nosofsky (2007), we did

According to the maximum-likelihood method the likelihood $L_{k}$ of an observed choice-vector given the application of a decision strategy $k$ and a constant error rate $\varepsilon_{k}$ is calculated by:

$L_{k}=p\left(n_{j k} \mid k, \varepsilon_{k}\right)=\prod_{j=1}^{J}\left(\begin{array}{c}n_{j} \\ n_{j k}\end{array}\right) \times\left(1-\varepsilon_{k}\right)^{n_{j k}} \times \varepsilon_{k}^{\left(n_{j}-n_{j k}\right)}$.

The six cue patterns are used as categories $J(J=6)$. The number of decisions in each category is denoted $n_{j}$. In Experiment 1 all $n_{j}=4$, in the other experiments all $n_{j}=8$. The number of observed choices in line with the prediction of the decision strategy $k$ is indicated by $n_{j k}$. The error rate $\varepsilon_{k}$ for strategy $k$ is estimated by:

$\hat{\varepsilon}_{k}=\left[\sum_{j=1}^{J}\left(n_{j}-n_{j k}\right)\right] \div\left[\sum_{j=1}^{J} n_{j}\right]$.

For WADD and PCS in cue pattern 4, option B was used as prediction. For EQW in cue patterns 1 to 3, random choice between A and B was implemented by using an error rate of .5. For individuals' error rates above .5 no likelihoods were computed.

6 For instance for an error rates of $30 \%$ for strategy application and cue hierarchy detection, the strategy classification was biased in favor of TTB by approximately $12 \%$, disfavoring WADD/PCS, and EQW by $7 \%$ and $5 \%$ respectively. 
not use simple $t$ - tests to compare decision times between "easy" (e.g., cue pattern 6) and "hard" (e.g., cue pattern 4) decision tasks. To test the predictions for all cue patterns simultaneously, for each individual, we correlated average decision times for the six cue patterns with the predictions of the models (i.e., TTB, PCS) and tested these correlations for significance which has higher power as compared to $t$ - tests (Glöckner, in press).

To account for deviations from normal distribution and to reduce the influence of outliers, decision times were log-transformed. The log-mean of decision times was 5.2 seconds (skew $=0.41$, $k u r t=-0.16$ ). Furthermore, decision times were re-sorted according to individuals' cue hierarchies measured in the post-test, so that, for instance, in cue pattern 1, the best cue always spoke against the second best cue (irrespectively of whether the best cue for a particular individual was state-capital or university). Individuals' mean decision times for the six cue patterns were correlated with the time predictions of TTB and PCS (Table 2). We tested the correlations against the null hypotheses that individuals used EQW and WADD $\left(H_{0(a)}: \rho=0\right)$ or TTB $\left(H_{0(b)}: \rho_{\mathrm{TTB}}=\rho_{\mathrm{PCS}}\right)$. The alternative hypothesis in both cases was that PCS was used. For the tests we used an increased alpha level of $\alpha=.20$ which allowed us to detect medium to large effects $(\rho=.4)$ with a power of .57 for $n=6$ observations using a one-tailed test (Faul \& Erdfelder, 1992). ${ }^{7}$ Participants that showed choices in line with EQW or WADD and for which $H_{0(a)}$ could be rejected were classified as PCS users; participants that showed choices in line with TTB and for which $H_{0(b)}$ could be rejected were classified as PCS users. In the rare cases in which the likelihood of the observed choice vector was equal for TTB and WADD (and PCS), participants were classified according to the highest absolute decision time correlation.

The overall strategy classification results are shown in Table 3 (first row). In line with our hypothesis, the majority of participants used weighted compensatory strategies. Eight participants (40\%) seemed to use PCS and three participants (15\%) used WADD. Seven participants (35\%) used an EQW heuristic. In contrast to earlier findings (Bröder \& Gaissmaier, 2007) only two participants used the non-compensatory TTB strategy. ${ }^{8}$

We refrained from using a compromise alpha level in which alpha and beta error are equal because then the alpha error would have been too high.

It has been argued that TTB might also be applied in combination with the recognition heuristic (Goldstein \& Gigerenzer, 1999). Thus, an individual might first use the cue "Do I know the city?" and then apply TTB with the remaining cues (e.g., state capital). Thus, we reran the analysis including the recognition cue which was taken from the check of the prior knowledge about the cities at the end of the experiment. The results remained stable. Only one former EQW user was now classified as TTB user. We decided to use TTB without the recognition heuristic for strategy classification in this and the following experiments because the additional recognition cue has validity in itself and for a fair test the cue should be included in the application of the other strategies, too. Furthermore, it has been shown in a similar paradigm that the recognition cue is not used in a non-compensatory way (Bröder \& Eichler, 2006). Finally, we did not have data on the ordinal validity of the recognition cue which would necessitate parameter fitting. The latter was found to lead to considerable biases in Monte-Carlo simulations. 


\begin{tabular}{lccccc}
\hline & \multicolumn{5}{c}{ Decision Strategies } \\
\cline { 2 - 6 } & TTB & EQW & PCS & WADD & RAND \\
\cline { 2 - 6 } Exp. 1 (instruction) & $2(10 \%)$ & $7(35 \%)$ & $8(40 \%)$ & $3(15 \%)$ & $0(0 \%)$ \\
Exp. 2 (time limit 3s) & $9(33 \%)$ & $5(19 \%)$ & $8(30 \%)$ & $4(15 \%)$ & $1(4 \%)$ \\
Experiment 3 & & & & $4(20 \%)$ & $1(5 \%)$ \\
Cond. 1 (time limit 12s) & $5(25 \%)$ & $6(30 \%)$ & $4(20 \%)$ & $1(5 \%)$ \\
Cond. 2 (time limit 6s) & $4(20 \%)$ & $8(40 \%)$ & $5(25 \%)$ & $2(10 \%)$ & $1(5 \%)$ \\
Cond. 3 (time limit 3s) & $4(20 \%)$ & $3(15 \%)$ & $7(35 \%)$ & $5(25 \%)$ & \\
\hline
\end{tabular}

Note: Due to rounding, the sum of percentages in a row may slightly differ from 100.

Decision times of the different strategy users were in line with the predictions derived for the strategies (Figure 4). There was an almost perfect correlation, $r=.97(p<.001)$, between the average decision time of PCS users and the predicted decision times. For the TTB user, this correlation was also very high, $r=.91(p<.001)$. This provides strong converging evidence for the strategy classification. Keep in mind, however, that for PCS users, the correlation was also used in the classification procedure, which might inflate the correspondence between these two measures in this condition.
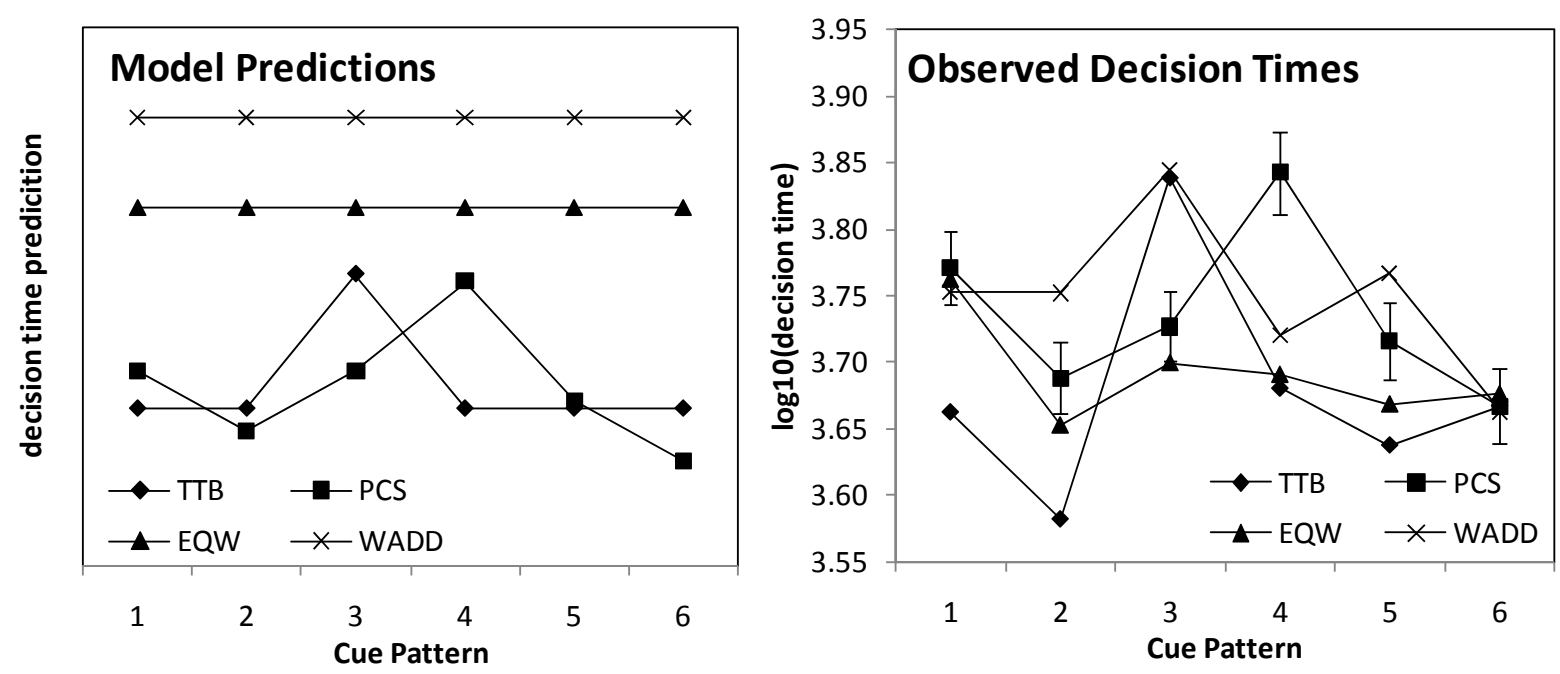

Figure 4. Model predictions for decision times (left) and log-transformed decision times in Experiment 1 (right) by cue patterns and individuals' decision strategies. The intercept and the scaling of the prediction curves are not determined by the models. For observed decision times, error bars indicate the SE. Error bars are shown for PCS only but SE was similar for all strategies. 
Confidence judgments. The mean observed confidence judgment for cue patterns 1 to 6 (with the $S E$ in parentheses) were 38.7 (6.9), 36.9 (7.0), 31.6 (6.5), 34.1 (7.0), 46.5 (7.3), and 44.5 (6.1). The confidence judgments generally show the inverse patterns of decision times. Accordingly, mean confidence judgments and mean decision times had a negative correlation $(r=-.62, p=$ .06). The cue patterns with the lowest inconsistencies and decision times showed the highest confidence judgments, and those with the highest inconsistencies and decision times showed the lowest confidence patterns (i.e., cue patterns 4 and 6). Note, that the considerable decrease in confidence judgments between cue patterns 4 and 6 could not be explained by TTB. According to TTB, in both cases, confidence should equal the validity of the differentiating cue (Gigerenzer, Hoffrage, \& Kleinbölting, 1991). In contrast, such a difference could be explained by PCS, because confidence judgments should be inversely related to inconsistency in the decision situation.

\section{Discussion}

According to Gigerenzer and Todd (1999), optimal conditions for the application of fast and frugal heuristics were realized in this experiment. Nevertheless, the results show that the majority of participants used weighted compensatory strategies (PCS and WADD) rather quickly and only a minority used TTB. These results conflict with Bröder and colleagues' (Bröder \& Gaissmaier, 2007; Bröder \& Schiffer, 2003b) conclusion that TTB dominates in memory-based probabilistic inferences. Their findings apparently do not generalize to situations in which familiar cues with natural cue validities and binary values are used and in which participants are highly motivated. Our data also challenge the assumption that people either have to ignore cue values or cue validities because of limited cognitive capacity. The results indicate that people are able to use both sources of information in at least reasonably complex decision situations - even in memorybased decisions in a weighted compensatory way. Because of low individual decision times, it is unlikely that information was integrated using solely deliberate computations. Further support for this idea also comes from the fact that decision times for PCS and WADD users were only slightly higher than decision times for TTB and EQW users. In line with our second hypothesis, the intuitive PCS accounted best for the decision behavior (choices and decision times) for a substantial proportion of the participants. On an aggregated level, decision times and confidence judgments provide converging evidence for the PCS model.

Decision time data also rule out the alternative explanation that individuals were already constructing knowledge about city sizes in the learning phase. Had this been the case, no systematic differences in decision times among cue patterns should be observed. The highly systematic variations of decision times in line with the PCS predictions make it also very unlikely that participants classified as PCS users applied complex compound cues (Garcia-Retamero, Hoffrage, \& Dieckmann, 2007) or used exemplars (Juslin \& Persson, 2002).

In a second experiment, we tested whether the results of Experiment 1 would also be found under severe explicit time limits. According to findings for outcome-based decisions (Payne et al., 
1988), extreme time limits lead to increased use of simplifying non-compensatory strategies. Thus, we might expect to see greater use of TTB. However, because PCS is based on automatic processes, it could also be expected that PCS would still be the predominantly used strategy, as was found for decisions made from readily available (non-memory-based) information (Glöckner \& Betsch, 2008c). Thus, from a theoretical as well as from an empirical perspective, no clear predictions favoring either TTB or PCS could be derived. We decided to start with the preliminary assumption that time limits would lead to a similar distribution of decision strategies as in Experiment 1.

\section{Experiment 2}

\section{Method}

Participants and design. Twenty-seven undergraduate students of the University of Oregon (16 female) between the ages of 18 and 25 years took part in the experiment. They were recruited and rewarded using the same procedure as in Experiment 1. Decision tasks were manipulated within subjects using a 6 (cue pattern) x 4 (version) x 2 (order of options) design. The "order of options" factor was added such that all city comparisons in Experiment 1 were presented twice with the order of cities being reversed to increase power in the analysis.

Materials and procedure. Essentially the same materials and procedure as in Experiment 1 were used. The only major change in the decision phase was that a dynamic down-counting time bar was added to the computer screen to provide an explicit time limit of 3 seconds. The length of the bar decreased proportionally to the elapsed decision time and changed color from green to red after 2.5 seconds. If a participant did not make a decision in time, a choice was no longer possible and the participant was instructed to decide faster the next time. Participants were instructed to make accurate decisions within the time limits. No confidence judgments were collected in this study.

\section{Results}

Learning success and manipulation check. The post-test showed that $84 \%$ of the answers in the post-test for knowledge about the cities were correct. Thus, the learning procedure was again successful. Again there was almost no prior knowledge concerning the cities (4\%), and only $24 \%$ of the city names were known to participants. Inspection of decision times revealed that $98.5 \%$ of the choices were made in time, thus the individuals followed the instructions to answer within the time limit. The log-mean of decision time was 1.7 seconds $($ skew $=-0.03$, kurt $=-0.6)$. Thus, the explicit time limit forced people to decide on average 3.5 seconds faster than under the implicit time pressure present in Experiment 1. 
Strategy classification. Choices and log-transformed decision times were analyzed using the same method as in the previous experiment. In the maximum-likelihood method ten participants showed choices in line with TTB, five in line with WADD/PCS, and eight in line with EQW. One person showed random choices. For three participants likelihoods for TTB and WADD/PCS were equal.

The overall results of the strategy classification are shown in Table 3 (second row). Nine participants used TTB. Eight participants still appeared to be using PCS. Five participants used EQW; four participants used WADD. In sum, although the proportion of TTB users was higher as in Experiment 1, compensatory strategies still predominated under severe time pressure and decision times of only 1.7 seconds.

To investigate the influence of the explicit time pressure on strategy classification, we compared the results of Experiment 1 and 2. The $\chi^{2}$ - test of independence between strategy classification (TTB, EQW, PCS, WADD) and experiment (i.e., either Experiment 1 or Experiment 2) was not significant, $\chi^{2}(N=46, d f=3)=4.22, p=.24$, although the manipulation of time pressure did have a sizable influence on decision times. Thus, it was not possible to reject the initial hypothesis that decision strategy selection remains stable under severe time limits. Note, however, that the power of the analysis was rather low.

Aggregated decision times were analyzed for the different strategy users (Figure 5). Mean decision times for PCS users were again in line with the predictions of the model, $r=.71, p<.05$. The same was true for TTB users, $r=.94, p<.001$.

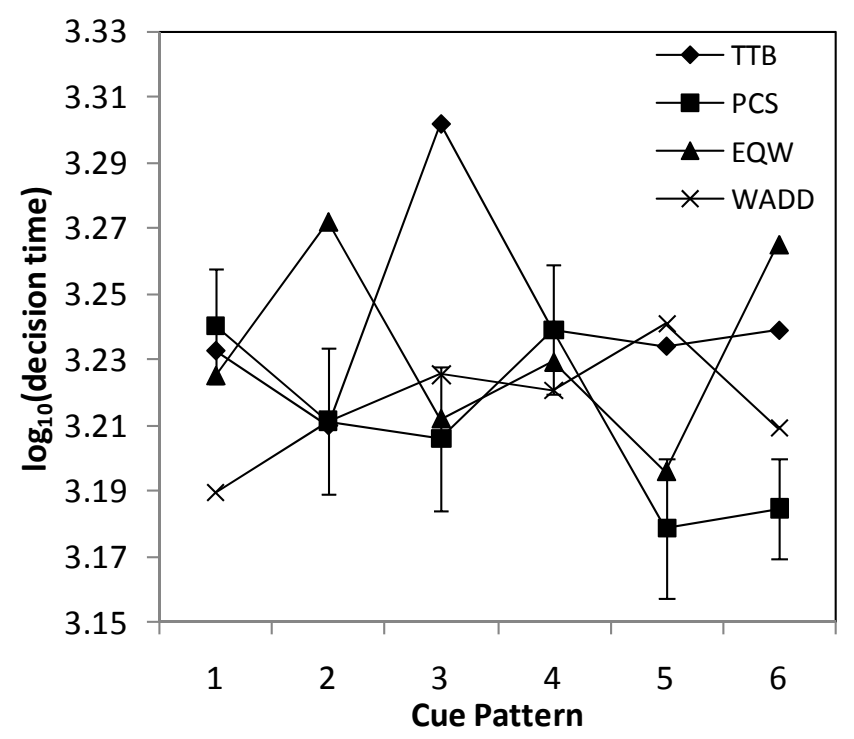

Figure 5. Log-transformed decision times in decisions under severe time pressure of 3 seconds (Exp. 2) by cue patterns for the different decision strategies. The error bars indicate the SE. Error bars are shown for PCS only but SE was similar for all strategies. The decision time predictions of the strategies are shown in the left graph of Figure 4. 


\section{Discussion}

Strategy selection under severe explicit time limits did not differ significantly from strategy selection under implicit time pressure (i.e., "respond as quickly as possible"). The results of Experiment 2 indicate a trend for TTB to be used more often under severe time limits, a finding that is in line with the predictions and previous findings of Payne et al. (1988; cf. Edland \& Svenson, 1993). However, even under severe time limits, and in an average decision time of 1.7 seconds, almost two-thirds of the participants made decisions reflecting use of compensatory strategies (PCS, WADD, and EQW). These participants' patterns of response suggested that they were activating all pieces of information from memory and integrating them. The decision times make it very unlikely that individuals could have applied deliberate sequential processes to carry out these calculations and to make the decisions, suggesting instead that intuitive decision strategies that rely on automatic processes might have been used. Furthermore, decision times of the participants classified as PCS users were once again highly correlated with the decision time predictions derived from the simulations. Taken together, the findings lend support to the PCS model.

One possible interpretation of the trend showing increased use of TTB is that the complex automatic processes postulated by PCS take longer than deliberate fast and frugal heuristics. Participants might have used TTB because the severe time limit did not allow for applying PCS. However, contrary to this explanation, a considerable proportion of participants appeared to use PCS and other compensatory strategies in this experiment. Examining the experimental situation more closely raises another possible explanation. Severe time limits can induce stress (Zakay, 1993). Besides limits on cognitive capacity, the increased stress level could have evoked an increased focus on more important information and thus the use of TTB. It has been repeatedly shown that increased stress levels lead to "tunneling" and focusing on fewer pieces of information (e.g., Broadbent, 1971; Keinan, 1987).

We aimed to investigate the effects of time limit more closely. Thus, we ran a third experiment using a between-subjects design manipulating the level of time pressure. We once again used the severe time limit condition which replicated Experiment 2, and included two additional conditions as comparisons: one in which decision time was also highly limited but somewhat less stringently than in Experiment 2 and, in fact, close to the actual mean amount of time that subjects took in Study 1, and another in which subjects had an explicit time limit, but one that gave them almost double the amount of time the average participant took in Study 1 under implicit time limits.

\section{Experiment 3}

\section{Method}

Participants and design. Sixty undergraduate students at the University of Oregon, who were recruited and rewarded as in Experiment 1 and 2, took part in the experiment. Participants were 
randomly assigned to one of the three conditions: a lenient (12 seconds), medium (6 seconds) or severe ( 3 seconds) time limit. Again, decision tasks were manipulated within subjects using a 6 (cue pattern) x 4 (version) x 2 (order of options) design.

Materials and procedure. Materials and procedure were essentially the same as in Experiment 2. The speed of the down-counting time bar was varied for the between-subjects time limit manipulation.

\section{Results}

The learning phase was again successful ( $87 \%$ correct answers). Prior knowledge about the cities was very similar to that in Experiments 1 and 2 (5\% prior knowledge, 24\% names known, 71\% unknown). Again, the individuals' choice vectors and decision times were analyzed for strategy classification, using the same method as in the previous experiments. The results are presented in Table 3 (third, fourth and fifth row). Once again, we found a high proportion of users of compensatory strategies under severe time limits, replicating Experiment 2. Yet in each of the three time limit conditions, compensatory strategies prevailed. There was no significant change in decision strategies (i.e., TTB, EQW, WADD, PCS) with increasing time pressure, $\chi^{2}(N=60, d f=$ $6)=4.54, p=.60$.

There was a substantial proportion of PCS users (overall 27\%) which was similar to that observed in Experiment 2 (26\%), but at a rate less than that observed when only implicit time pressure was present (Experiment 1: 40\%). This might be partially due to the fact that explicit time limits blur the effects on decision times. Thus, the proportion of PCS users is likely to be underestimated in the lenient and medium time limit conditions and there is a high likelihood that PCS users might not be detected (and instead erroneously classified as WADD users). Note that even in the low time pressure condition, observed decision times of 2.6 seconds made it very unlikely that a WADD strategy was deliberately applied (cf. Lohse \& Johnson, 1996).

Inspection of mean decision times revealed that all three time limit conditions led to generally low decision times. The log-means of decision times for the three conditions (log-values with $S E$ in parentheses) were 1.70 seconds $\left(M_{\text {Log }}=3.21, S d=0.22\right), 2.39$ seconds $\left(M_{\text {Log }}=3.38, S d=\right.$ $0.17)$, and 2.61 seconds $\left(M_{\log }=3.42, S d=0.23\right) .{ }^{9}$ More than $99 \%$ of the choices were completed in time. Mean decision times of the strategy users were again correlated with the predictions of the respective strategies. The correlation of PCS and TTB users for the time limit conditions were respectively $r_{P C S}=.74 / r_{T T B}=.88$ (lenient), $r_{P C S}=.50 / r_{T T B}=.67$ (medium), and $r_{P C S}=.91$ $/ r_{T T B}=.35$ (severe). Decision time results are presented in Figure 6.

9 Due to a programming error, six decision times for the first and six other decision times for the second occurrence of each version of each decision task were not recorded, resulting in 36 instead of 48 recorded decision times. 

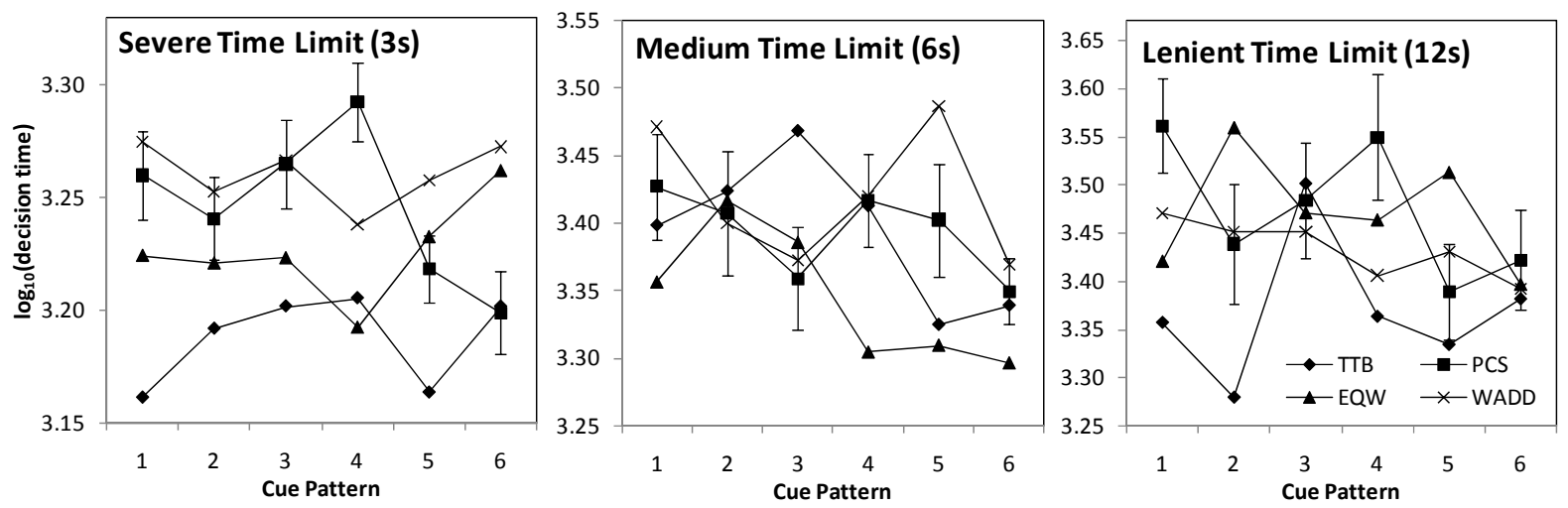

Figure 6. Log-transformed decision times in decisions under different time pressure conditions (Exp. 3). The error bars indicate the SE. Error bars are shown for PCS only. The decision time predictions of the different strategies are shown in the left graph of Figure 4.

\section{Discussion}

The results replicate and extend the findings of the previous experiments. In all three time limit conditions, compensatory strategies predominated. A considerable proportion of participants showed decisions and decision times in line with the predictions of PCS. Consistent with the theoretical consideration about properties of intuitive processes (Hammond et al., 1987) and in line with recent findings in decisions from given information (Glöckner \& Betsch, 2008c) the time limit manipulation did not have a significant effect on decision strategies. Many individuals seem to use intuitive decision strategies that allow for weighted compensatory information integration from the beginning (cf. WADD as default strategy, Bröder, 2003). Participants seem to be able to use these strategies even under severe time limits; but they also apply them under lenient time limits in order to decide quickly. In the latter case the available time is only partially used.

\section{General Discussion}

In this paper we investigated decision strategies in memory-based decisions using the city-size task. Specifically, we tested whether compensatory strategies such as the PCS model or the noncompensatory TTB heuristic could better account for memory-based decision behavior under different time pressure conditions. We first derived choice and decision time predictions by conducting simulations for PCS. We ran three experiments to test these predictions at an aggregated level and to test strategy usage at an individual level. In line with earlier findings, we observed high inter-individual heterogeneity in strategy usage. Under all conditions, we found a substantial proportion of TTB users (overall 22\%) who showed choices and decision times very much in line with the predictions of the strategy. However, in contrast to earlier findings, the majority of individuals appeared to apply compensatory strategies in our studies. Overall, $30 \%$ of the participants' decision times and choices were best explained by the PCS model. An additional 17\% 
showed WADD choices with response times that make it very unlikely that weighted sums were deliberately calculated. Finally, 27\% of the participants appeared to use an EQW strategy.

It was found that time pressure had no significant effect on strategy choice, although, when comparing the results of Experiment 1 with the remaining experiments, there was a trend toward increased use of simple non-compensatory strategies such as TTB when explicit time limits were applied. However, even with severe time limits and decision times as low as 1.7 seconds, the majority of participants used compensatory strategies. It is very unlikely that in such a short time the necessary pieces of information are deliberately retrieved from memory and serially integrated. This indicates that intuitive strategies might have been used which are not bound by cognitive capacity constraints (cf. Beilock \& DeCaro, 2007). In line with the predictions by Hammond et al. (1987), and as derived from our simulation, intuitive-automatic decision strategies seem to integrate information in a weighted compensatory way. The almost perfect correlations between decision time predictions of the PCS model and the observed data indicates that the PCS model is a good candidate to explain these processes. Thus, the findings add to the growing body of evidence supporting parallel constraint satisfaction approaches in decision making (e.g., Holyoak \& Simon, 1999).

Note that for pragmatic reasons in the current studies, the PCS model was used without taking into account individual differences in cue validities when fitting its parameters. Furthermore, the power for detecting differences in decision times in strategy classification was rather low and the strategy classification favored TTB. Finally, wrong explications of cue validities by participants are likely to have produced further misclassifications in favor of EQW. Thus, the proportion of PCS users is likely to be considerably underestimated in the reported studies.

Additional tests should be run to test the PCS model against other comprehensive decision models such as decision field theory (Busemeyer \& Townsend, 1993), image theory (Beach \& Mitchell, 1996), and prototype or exemplar models (Dougherty, Gettys, \& Ogden, 1999). Our findings indicate that a model for memory-based decision making should be able to account for fast weighted compensatory information integration and systematic differences in decision times.

The application of TTB to memory-based decisions in the city-size task has been explicitly hypothesized (Gigerenzer \& Todd, 1999). However, our results show that the findings by Bröder and colleagues (Bröder \& Gaissmaier, 2007; Bröder \& Schiffer, 2003b) in favor of a dominant TTB use in memory-based decision do not generalize to decision tasks in which (a) cues have natural cue validities which are easy to access and have binary cue values, and in which (b) differences between cue validities are not artificially increased by explicit information about their predictive power. In line with our expectations, this allowed individuals to apply intuitive decision strategies which quickly integrate information and seem to be less prone to time pressure induced capacity constraints.

Intuitive strategies like PCS rely on the possibility for a quick activation of information in memory. A comparison of our findings with Bröder and colleagues' results indicates that the accessi- 
bility of information might be an important moderating factor for strategy selection in memorybased decisions. Frugal strategies that rely on one cue only seem to be used more often if the retrieval of information is more effortful because cue values and cue validities are not so easy to access. In our studies, we tried to realize an externally valid decision situation: We did not induce cue validities by instruction or by lengthy cue validity learning phases, but we used individuals' own cue hierarchies which they had learned in the real world. Nevertheless, the prevalence rate of TTB was surprisingly low.

Based on the reported results and other findings in decisions from given information (e.g., Bröder, 2000; Bröder, 2003; Glöckner \& Betsch, 2008a, 2008c; Newell et al., 2003), the ubiquity of simple fast and frugal heuristics seems to be overestimated (Gigerenzer, 2004). By focusing on the "simplifying approach" to decision making, in a parallel fashion, alternative decision strategies which are based on complex automatic information integration processes may have been underestimated. The reported results speak for the importance of intuitive strategies that integrate many pieces of information quickly using automatic processes. As suggested many years ago (e.g., Brunswik, 1955; Wertheimer, 1938), automatic processes that may have evolved from processes of perception seem to play a particularly important role in human cognition. The PCS model integrates such processes in a decision strategy and was supported by the data. 


\section{References}

Beach, L. R., \& Mitchell, T. R. (1996). Image theory, the unifying perspective. In L. R. Beach (Ed.), Decision making in the workplace: A unified perspective (pp. 1-20). Hillsdale, NJ, England: Lawrence Erlbaum Associates, Inc.

Beilock, S. L., \& DeCaro, M. S. (2007). From poor performance to success under stress: Working memory, strategy selection, and mathematical problem solving under pressure. Journal of Experimental Psychology: Learning, Memory, and Cognition, 33(6), 983-998.

Bergert, F. B., \& Nosofsky, R. M. (2007). A Response-Time Approach to Comparing Generalized Rational and Take-the-Best Models of Decision Making. Journal of Experimental Psychology: Learning, Memory, and Cognition, 33(1), 107-129.

Broadbent, D. E. (1971). Decision and stress. Decision and stress. xiv, 522 pp. Oxford, England: Academic Press Academic Press Print.

Bröder, A. (2000). Assessing the empirical validity of the "Take-the-best" heuristic as a model of human probabilistic inference. Journal of Experimental Psychology: Learning, Memory, and Cognition, 26(5), 1332-1346.

Bröder, A. (2003). Decision making with the "adaptive toolbox": Influence of environmental structure, intelligence, and working memory load. Journal of Experimental Psychology: Learning, Memory, and Cognition, 29(4), 611-625.

Bröder, A., \& Eichler, A. (2006). The use of recognition information and additional cues in inferences from memory. Acta Psychologica, 121(3), 275-284.

Bröder, A., \& Gaissmaier, W. (2007). Sequential processing of cues in memory-based multiattribute decisions. Psychonomic Bulletin \& Review, 14(5), 895-900.

Bröder, A., \& Schiffer, S. (2003a). Bayesian strategy assessment in multi-attribute decision making. Journal of Behavioral Decision Making, 16(3), 193-213.

Bröder, A., \& Schiffer, S. (2003b). Take The Best versus simultaneous feature matching: Probabilistic inferences from memory and effects of reprensentation format. Journal of Experimental Psychology: General, 132(2), 277-293.

Bröder, A., \& Schiffer, S. (2006). Stimulus Format and Working Memory in Fast and Frugal Strategy Selection. Journal of Behavioral Decision Making, 19(4), 361-380.

Brunswik, E. (1955). Representative design and the probability theory in a functional psychology. Psychological Review, 62, 193-217. 
Busemeyer, J. R., \& Townsend, J. T. (1993). Decision field theory: A dynamic-cognitive approach to decision making in an uncertain environment. Psychological Review, 100(3), 432-459.

Dougherty, M. R. P., Gettys, C. F., \& Ogden, E. E. (1999). MINERVA-DM: A memory processes model for judgments of likelihood. Psychological Review, 106(1), 180-209.

Edland, A., \& Svenson, O. (1993). Judgment and decision making under time pressure: Studies and findings. In O. Svenson \& A. J. Maule (Eds.), Time pressure and stress in human judgment and decision making (pp. 27-40). New York, NY: Plenum Press.

Faul, F., \& Erdfelder, E. (1992). G-Power: A priori, post-hoc, and compromise power analysis for MS DOS [Computer program]. Bonn, Germany: University of Bonn, Department of Psychology.

Fazio, R. H. (1990). A practical guide to the use of response latency in social psychological research. In C. Hendrick \& M. S. Clark (Eds.), Research methods in personality and social psychology (pp. 74-97). Thousand Oaks, CA: Sage Publications, Inc.

Fishburn, P. C. (1974). Lexicographic orders, utilities, and decision rules: A survey. Management Science, 20, 1442-1472.

Garcia-Retamero, R., Hoffrage, U., \& Dieckmann, A. (2007). When one cue is not enough: Combining fast and frugal heuristics with compound cue processing. The Quarterly Journal of Experimental Psychology, 60(9), 1197-1215.

Gigerenzer, G. (2004). Fast and frugal heuristics: The tools of bounded rationality. In D. J. Koehler \& N. Harvey (Eds.), Blackwell handbook of judgment and decision making (pp. 62-88). Malden, MA: Blackwell Publishing.

Gigerenzer, G., \& Goldstein, D. G. (1996). Reasoning the fast and frugal way: Models of bounded rationality. Psychological Review, 103(4), 650-669.

Gigerenzer, G., \& Goldstein, D. G. (1999). Betting on one good reason: The take the best heuristic. In Simple heuristics that make us smart (pp. 75-95). New York, NY: Oxford University Press.

Gigerenzer, G., Hoffrage, U., \& Kleinbölting, H. (1991). Probabilistic mental models: A Brunswikian theory of confidence. Psychological Review, 98(4), 506-528.

Gigerenzer, G., \& Todd, P. M. (1999). Simple heuristics that make us smart. Evolution and cognition. New York, NY: Oxford University Press.

Glöckner, A. (2006). Automatische Prozesse bei Entscheidungen [Automatic processes in decision making]. Hamburg, Germany: Kovac. 
Glöckner, A. (in press). Multiple measure strategy classification: Outcomes, decision times and confidence ratings. In A. Glöckner \& C. L. M. Witteman (Eds.), Tracing intuition: Recent methods in measuring intuitive and deliberate processes in decision making. London: Psychology Press \& Routledge.

Glöckner, A., \& Betsch, T. (2008a). Do people make decisions under risk based on ignorance? An empirical test of the Priority Heuristic against Cumulative Prospect Theory. Organizational Behavior and Human Decision Processes, 107(1), 75-95.

Glöckner, A., \& Betsch, T. (2008b). Modeling option and strategy choices with connectionist networks: Towards an integrative model of automatic and deliberate decision making. Judgment and Decision Making, 3(3), 215-228.

Glöckner, A., \& Betsch, T. (2008c). Multiple-reason decision making based on automatic processing. Journal of Experimental Psychology: Learning, Memory, and Cognition, 34(5), 1055-1075.

Glöckner, A., Betsch, T., \& Schindler, N. (under review). Coherence shifts in probabilistic inference tasks.

Goldstein, D. G., \& Gigerenzer, G. (1999). The recognition heuristic: How ignorance makes us smart. In Simple heuristics that make us smart (pp. 37-58). New York, NY: Oxford University Press.

Hammond, K. R., Hamm, R. M., Grassia, J., \& Pearson, T. (1987). Direct comparison of the efficacy of intuitive and analytical cognition in expert judgment. IEEE Transactions on Systems, Man, \& Cybernetics, 17(5), 753-770.

Holyoak, K. J., \& Simon, D. (1999). Bidirectional reasoning in decision making by constraint satisfaction. Journal of Experimental Psychology: General, 128(1), 3-31.

Juslin, P., \& Persson, M. (2002). PROBabilities from EXemplars (PROBEX): A "lazy" algorithm for probabilistic inference from generic knowledge. Cognitive Science: A Multidisciplinary Journal, 26(5), 563-607.

Kahneman, D., \& Frederick, S. (2002). Representativeness revisited: Attribute substitution in intuitive judgment. In T. Gilovich, D. Griffin \& D. Kahneman (Eds.), Heuristics and biases: The psychology of intuitive judgment (pp. 49-81). New York, NY: Cambridge University Press.

Keinan, G. (1987). Decision making under stress: Scanning of alternatives under controllable and uncontrollable threats. Journal of Personality and Social Psychology, 52(3), 639-644. 
Lee, M. D., \& Cummins, T. D. R. (2004). Evidence accumulation in decision making: Unifying the "take the best" and the "rational" models. Psychonomic Bulletin \& Review, 11(2), 343352.

Lohse, G. L., \& Johnson, E. J. (1996). A comparison of two process tracing methods for choice tasks. Organizational Behavior and Human Decision Processes, 68(1), 28-43.

McClelland, J. L., \& Rumelhart, D. E. (1981). An interactive activation model of context effects in letter perception: I. An account of basic findings. Psychological Review, 88(5), 375-407.

Montgomery, H. (1989). From cognition to action: The search for dominance in decision making. In H. Montgomery \& O. Svenson (Eds.), Process and structure in human decision making (pp. 23-49). Oxford, England: John Wiley \& Sons.

Newell, B. R., Weston, N. J., \& Shanks, D. R. (2003). Empirical tests of a fast-and-frugal heuristic: Not everyone "takes-the-best". Organizational Behavior and Human Decision Processes, 91(1), 82-96.

Payne, J. W., Bettman, J. R., \& Johnson, E. J. (1988). Adaptive strategy selection in decision making. Journal of Experimental Psychology: Learning, Memory, and Cognition, 14(3), 534-552.

Rieskamp, J. (2006). Perspectives of Probabilistic Inferences: Reinforcement Learning and an Adaptive Network Compared. Journal of Experimental Psychology: Learning, Memory, and Cognition, 32(6), 1355-1370.

Rieskamp, J., \& Hoffrage, U. (1999). When do people use simple heuristics, and how can we tell? In Simple heuristics that make us smart (pp. 141-167). New York, NY: Oxford University Press.

Schneider, W., \& Shiffrin, R. M. (1977). Controlled and automatic human information processing: I. Detection, search, and attention. Psychological Review, 84(1), 1-66.

Shultz, T. R., \& Lepper, M. R. (1996). Cognitive dissonance reduction as constraint satisfaction. Psychological Review, 103(2), 219-240.

Simon, D., Pham, L. B., Le, Q. A., \& Holyoak, K. J. (2001). The emergence of coherence over the course of decision making. Journal of Experimental Psychology: Learning, Memory, and Cognition, 27(5), 1250-1260.

Simon, D., Snow, C. J., \& Read, S. J. (2004). The Redux of Cognitive Consistency Theories: Evidence Judgments by Constraint Satisfaction. Journal of Personality and Social Psychology, 86(6), 814-837. 
Svenson, O. (1992). Differentiation and Consolidation Theory of human decision making: A frame of reference for the study of pre- and post-decision processes. Acta Psychologica, $80(1-3), 143-168$.

Thagard, P. (1989). Explanatory coherence. Behavioral and Brain Sciences, 12(3), 435-502.

Thagard, P., \& Millgram, E. (1995). Inference to the best plan: A coherence theory of decision. In A. Ram \& D. B. Leake (Eds.), Goal-driven learning (pp. 439-454). Cambridge, MA: MIT Press.

Tversky, A. (1972). Elimination by aspects: A theory of choice. Psychological Review, 79(4), 281-299.

Wasserman, L. (2000). Bayesian model selection and model averaging. Journal of Mathematical Psychology, 44(1), 92-107.

Wertheimer, M. (1938). Gestalt theory. In W. D. Ellis (Ed.), A source book of Gestalt psychology (pp. 1-11). London, England: Kegan Paul, Trench, Trubner \& Company Kegan Paul, Trench, Trubner \& Company Print.

Zakay, D. (1993). The impact of time perception processes on decision making under time stress. In O. Svenson \& A. J. Maule (Eds.), Time pressure and stress in human judgment and decision making (pp. 59-72). New York, NY: Plenum Press. 


\section{Preprints 2009}

Niels Petersen: Review Essay - How Rational is International Law? 2009/16.

Felix Bierbrauer: On the legitimacy of coercion for the financing of public goods. 2009/15.

Feri / Irlenbusch / Sutter: Efficiency Gains from Team-Based Coordination - Large-Scale Experimental Evidence.2009/14.

Jos Jansen: On Competition and the Strategic Management of Intellectual Property in Oligopoly. 2009/13.

Martin Hellwig: Utilitarian Mechanism Design for an Excludable Public Good. 2009/12.

Philipp Weinschenk: Persistence of Monopoly and Research Specialization. 2009/11.

Nina Horstmann/Andrea Ahlgrimm/Andreas Glöckner: How Distinct are Intuition and Deliberation? An Eye-Tracking Analysis of Instruction-induced Decision Modes. 2009/10.

Thorsten Lübbers: Is Cartelisation Profitable? A Case Study of the Rhenish Westphalian Coal Syndicate, 1893-1913. 2009/9.

Andreas Glöckner/Bernd Irlenbusch/Sebastian Kube/Andreas Nicklisch/Hans-Theo Normann: Leading with(out) Sacrifice?

A Public-Goods Experiment with a Super-Additive Player. 2009/8.

Carl Christian von Weizsäcker: Asymmetrie der Märkte und Wettbewerbsfreiheit. 2009/7.

Jos Jansen: Strategic Information Disclosure and Competition for an Imperfectly Protected Innovation. 2009/6.

forthcoming in: Journal of Industrial Economics

Niels Petersen: Abkehr von der internationalen Gemeinschaft? - Die aktuelle Rechtsprechung des US Supreme Court zur innerstaatlichen Wirkung von völkerrechtlichen Verträgen. 2009/5.

Johannes Rincke / Christian Traxler: Deterrence Through Word of Mouth. 2009/4.

Christian Traxler/ Joachim Winter: Survey Evidence on Conditional Norm Enforcement. 2009/3.

Britta Herbig / Andreas Glöckner: Experts and Decision Making: First Steps Towards a Unifying Theory of Decision Making in Novices, Intermediates and Experts. 2009/2.

Martin Beckenkamp: Environmental dilemmas revisited: structural consequences from the angle of institutional ergonomics. 2009/1.

\section{Preprints 2008}

Carsten Burhop: The Underpricing of Initial Public Offerings in Imperial Germany, 1870-1896. 2008/46.

Martin Hellwig: A Note on Deaton's Theorem on the Undesirability of Nonuniform Excise Taxation. 2008/45.

Martin Hellwig: Zur Problematik staatlicher Beschränkungen der Beteiligung und der Einflussnahme von Investoren bei großen Unternehmen. 2008/44.

published in: Zeitschrift für das gesamte Handelsrecht und Wirtschaftsrecht 172 (2008), 768 - 787

Martin Hellwig: Systemic Risk in the Financial Sector: An Analysis of the Subprime-Mortgage Financial Crisis. 2008/43.

Andreas Glöckner / Ann-Katrin Herbold: Information Processing in Decisions under Risk: Evidence for Compensatory Strategies based on Automatic Processes. 2008/42.

Jörn Lüdemann / Stefan Magen: Effizienz statt Gerechtigkeit? 2008/41.

Christoph Engel: Die Bedeutung der Verhaltensökonomie für das Kartellrecht. 2008/40.

Felix Bierbrauer: A unified approach to the revelation of public goods preferences and to optimal income taxation. 2008/39.

Carsten Burhop / Thorsten Lübbers: Incentives and Innovation? R\&D Management in Germany's High-Tech Industries During the Second Industrial Revolution. 2008/38.

Andreas Nicklisch / Tobias Salz: Reciprocity and status in a virtual field experiment. 2008/37. 
Andreas Glöckner / Christoph Engel: Can We Trust Intuitive Jurors? An Experimental Analysis. 2008/36.

Jörn Lüdemann: Wettbewerb und Regulierung in der Telekommunikation. Das Telekommunikationsrecht vor den Herausforderungen dynamischer Märkte. 2008/35.

published in: Jörn Lüdemann (Hrsg.), Telekommunikation, Energie, Eisenbahn - Welche Regulierung brauchen die Netzwirtschaften? Tübingen (Mohr Siebeck) 2008, S. 69-99

Martin Beckenkamp: Playing strategically against nature? - Decisions viewed from a game-theoretic frame. 2008/34.

Christoph Engel: Preponderance of the Evidence versus Intime Conviction. A Behavioural Perspective on a Conflict between American and Continental European Law? 2008/33.

Kristoffel Grechenig: Schadenersatz bei Verletzung von $\S 14 \mathrm{WpHG}$ ? Insiderhandel mit positiver und negativer Information. 2008/32.

Felix Bierbrauer: Optimal Income Taxation, Public Goods Provision and Robust Mechanism Design. 2008/31.

Hans-Theo Normann: Vertical Integration, Raising Rivals' Costs and Upstream Collusion. 2008/30. forthcoming in: European Economic Review

Martin Hellwig: Competition Policy and Sector-Specific Regulation for Network Industries. 2008/29.

forthcoming in: X. Vives (ed.), "Competition Policy in the EU: Fifty Years on from the Treaty of Rome" Oxford University Press.

Niels Petersen: Rational Choice or Deliberation? - Customary International Law between Coordination and Constitutionalization. 2008/28.

forthcoming in: Journal of Institutional and Theoretical Economics 165 (2009)

Stephen Broadberry / Carsten Burhop: Resolving the Anglo-German Industrial Productivity Puzzle, 1895-1935:

A Response to Professor Ritschl. 2008/27.

forthcoming in: Journal of Economic History

Niels Petersen: Demokratie und Grundgesetz - Veränderungen des Demokratieprinzips in Art. 20 Abs. 2 GG angesichts der Herausforderungen moderner Staatlichkeit. 2008/26.

forthcoming: Jahrbuch des öffentlichen Rechts der Gegenwart 57 (2009)

Andreas Nicklisch: Semi-collusive advertising and pricing in experimental duopolies. 2008/25.

Andreas Nicklisch: Inequity Aversion, Reciprocity, and Appropriateness in the Ultimatum-Revenge Game. 2008/24.

Christoph Engel: The Behaviour of Corporate Actors. A Survey of the Empirical Literature. 2008/23.

Emanuel Vahid Towfigh: Komplexität und Normenklarheit - oder: Gesetze sind für Juristen gemacht. 2008/22.

Christian Traxler / Andreas Reutter: Apportionment, Fiscal Equalization and Decentralized Tax Enforcement. 2008/21.

Christoph Engel, REITs ante portas. Die Anpassung des deutschen Rechts an institutionelle Investoren in den Grundstücks- und Mietmärkten. 2008/20.

forthcoming in: Juristenzeitung

Christoph Engel, Ernst-Joachim Mestmäcker. 2008/19.

forthcoming in: Stefan Grundmann / Karl Riesenhuber (eds.): Deutschsprachige Zivilrechtslehrer des 20. Jahrhunderts in Berichten ihrer Schüler, Band 2, Berlin (De Gruyter) 